\title{
Angioplasty Outcomes in the Elderly Nepalese Patients: an eight years experience in Norvic International Hospital
}

\author{
Chirag G, Rawat B, Rajbhandari S, Bhatta Y, Jaiswal JP, Vaidya A
}

\section{Address for correspondence :}

Dr Chirag Gurung

Norvic International Hospital, Thapathali, Kathmandu

E-mail-chiraggurung@hotmail.com

\section{ABSTRACT \\ Background}

The aim of the study is to evaluate and compare the outcomes of percutaneous transluminal coronary angioplasty (PTCA) between the elderly (>70 yrs) and the non-elderly (70 yrs and younger) Nepalese patients who had been admitted to Norvic International Hospital between early 2002 and April 2010.

\section{Methods}

Data of a total of 92 elderly and 604 non-elderly patients were retrospectively analyzed after they had been admitted in the Hospital for the interventional treatment of acute coronary syndrome.

\section{Results}

There were 64 (69.6\%) male patients and 28 (30.4\%) female patients in the elderly group. Elderly population had lesser smokers. Diabetic population was similar in both the age groups. The elderly patients slightly less success rate compared to the non-elderly (95.7\% vs. 99.3\%). There was no significant difference in bleeding complication and groin haematoma. In hospital death was $3.33 \%$ in elderly and $0.5 \%$ in non elderly.

\section{Conclusion}

Though the outcome in the elderly is poorer in comparison to the younger patients, it is an expected result when compared to even the biggest centres worldwide. 


\section{Introduction}

Ischemic heart disease is one of the leading causes of death in any part of the world regardless of whether it's a developed country or a developing country like Nepal. Among all groups of people, the elderly especially have been undertreated with aggressive interventional procedures due to the fear of unfavourable events and of beliefs that it is less beneficial to the elderly, especially since it is known that cardiovascular morbidity and mortality rate rises up with age.

Percutaneous Transluminal Coronary Angioplasty (PTCA) which was first developed in 1977 by Andreas Gruentzig in Switzerland was first introduced to Nepal in the year 2002 by Norvic International Hospital. Since then, it has been widely practiced in the hospital and has been gaining popularity due to the fact that there are fewer complications, risks and less invasive compared to other surgical procedures such as coronary artery bypass graft (CABG).

PTCA involves opening of the blocked artery with a stent which helps to keep it open. This technique is performed to dilate the area of arterial blockage with the help of a catheter with an inflatable balloon at its tip. Prior to performing a PTCA the exact location and type of the blockage have to be determined which is done by a preprocedure Coronary Angiography (CAG).

Norvic has been providing coronary interventional services to all patients of all ages. The aim of this study was to assess the outcomes of PTCA in the elderly Nepalese patients and to compare the outcome with the studies from other international centres.

\section{Methods}

Norvic International Hospital has been a pioneer hospital in the field of cardiology in Nepal with procedures such as cardiac catheterizations and angioplasties done routinely. For this study, a total of 696 consecutive patients who were admitted in the Norvic Hospital for the interventional treatment of acute coronary syndromes between 2002 and April 2010 were analyzed. Data was retrieved from the cathlab database.

The participants were classified according to their age into Elderly (Over 70 years) and Non-elderly (70 years and below). Presence of risk factors such as hypertension, diabetes and dyslipidemia was noted.

Outcome of the procedure was considered successful if a normal antegrade flow was noted after the procedure. Major complications included in-hospital death, sub/acute thrombosis, life-threatening arrhythmia (VT/VF) and minor complications included gastro-intestinal bleeding and groin hematoma formation, and need for blood transfusion.

\section{Results}

A total of 696 patients had undergone PTCA between early 2002 and April 2010. There were 92 elderly (>70 years) patients while the remaining 604 were aged 70 years or younger. The risk factors profile of the elderly (Table 1) show they were less likely to be smokers, diabetic, dyslipidemic or with a positive family history. But they were more likely to be hypertensive. The proportion of females was considerably higher in the elderly group.

Table 1: Risk Factors in the elderly (>70 years) and Nonelderly (70 years and younger) patients

\begin{tabular}{|c|c|c|c|c|c|c|}
\hline & \multicolumn{2}{|c|}{ Elderly } & \multicolumn{2}{|c|}{ Non-Elderly } & \multirow{2}{*}{$\begin{array}{l}\text { Odds ratio } \\
(95 \% \mathrm{Cl})\end{array}$} & \multirow{2}{*}{ p-value } \\
\hline Sex & $\mathbf{N}$ & $\%$ & $\mathbf{N}$ & $\%$ & & \\
\hline Male & 64 & $69.6 \%$ & 506 & $83.8 \%$ & \multirow{2}{*}{$0.4(0.3-0.7)$} & \multirow{2}{*}{0.001} \\
\hline Female & 28 & $30.4 \%$ & 98 & $16.2 \%$ & & \\
\hline \multicolumn{7}{|c|}{ Smoking } \\
\hline Yes & 15 & $16.3 \%$ & 216 & $35.8 \%$ & \multirow{2}{*}{$0.3(0.2-0.6)$} & \multirow{2}{*}{$<0.001$} \\
\hline No & 77 & $83.7 \%$ & 388 & $64.2 \%$ & & \\
\hline \multicolumn{7}{|c|}{ Hypertension } \\
\hline Yes & 70 & $76.1 \%$ & 390 & $64.6 \%$ & \multirow{2}{*}{$1.7(1.0-2.9)$} & \multirow{2}{*}{0.030} \\
\hline No & 22 & $23.9 \%$ & 214 & $35.4 \%$ & & \\
\hline \multicolumn{7}{|c|}{ Diabetes } \\
\hline Yes & 31 & $33.7 \%$ & 226 & $37.4 \%$ & \multirow{2}{*}{$0.8(0.5-1.3)$} & \multirow{2}{*}{0.491} \\
\hline No & 61 & $66.3 \%$ & 378 & $62.6 \%$ & & \\
\hline \multicolumn{7}{|c|}{ Dyslipidemia } \\
\hline Yes & 22 & $23.9 \%$ & 205 & $33.9 \%$ & \multirow{2}{*}{$0.6(0.4-1.0)$} & \multirow{2}{*}{0.056} \\
\hline No & 70 & $76.1 \%$ & 399 & $66.1 \%$ & & \\
\hline \multicolumn{7}{|c|}{ Family History } \\
\hline Yes & 3 & $3.3 \%$ & 59 & $9.8 \%$ & \multirow{3}{*}{$0.3(0.01-1.0)$} & \multirow{3}{*}{0.041} \\
\hline No & 89 & $96.7 \%$ & 545 & $90.2 \%$ & & \\
\hline Total & 92 & $100.0 \%$ & 604 & $100.0 \%$ & & \\
\hline
\end{tabular}

Table 2 gives the outcomes and complications after the angioplasty procedure. The elderly patients slightly less success rate compared to the non-elderly $(95.7 \%$ vs. 99.3\%). There were an equal number of in-hospital deaths ( 3 each) but proportionately, there were more deaths in the elderly group. Comparatively, minor complications were present more in the non-elderly group.

Table 2: Outcome and complications in the elderly (>70 years) and non-elderly (70 years or younger patients)

\begin{tabular}{|c|c|c|c|c|c|c|}
\hline & \multicolumn{2}{|c|}{ Elderly } & \multicolumn{2}{|c|}{ Non-Elderly } & \multirow{2}{*}{$\begin{array}{l}\text { Odds ratio } \\
(95 \% \mathrm{Cl})\end{array}$} & \multirow{2}{*}{ p-value } \\
\hline & $\mathbf{N}$ & $\%$ & $\mathbf{N}$ & $\%$ & & \\
\hline \multicolumn{7}{|l|}{ Outcomes } \\
\hline Successful & 88 & $95.7 \%$ & 600 & $99.3 \%$ & \multirow{2}{*}{$0.2(0.1-0.6)$} & \multirow{2}{*}{0.013} \\
\hline Unsuccessful & 4 & $4.3 \%$ & 4 & $0.7 \%$ & & \\
\hline \multicolumn{7}{|c|}{ In-hospital death } \\
\hline Yes & 3 & $3.3 \%$ & 3 & $0.5 \%$ & \multirow{2}{*}{$6.7(1.3-33.9)$} & \multirow{2}{*}{0.033} \\
\hline No & 89 & $96.7 \%$ & 601 & $99.5 \%$ & & \\
\hline \multicolumn{7}{|c|}{ Sub/Acute Thrombosis } \\
\hline Yes & 0 & $0.0 \%$ & 3 & $0.5 \%$ & \multirow[b]{2}{*}{ - } & \multirow{2}{*}{1.000} \\
\hline No & 92 & $100.0 \%$ & 601 & $99.5 \%$ & & \\
\hline \multicolumn{7}{|l|}{ VT/VF } \\
\hline Yes & 1 & $1.1 \%$ & 1 & $0.2 \%$ & \multirow{2}{*}{$\begin{array}{c}6.6(0.4- \\
106.8)\end{array}$} & \multirow{2}{*}{0.247} \\
\hline No & 91 & $98.9 \%$ & 603 & $99.8 \%$ & & \\
\hline \multicolumn{7}{|c|}{ Blood Transfusion } \\
\hline Yes & 0 & $0.0 \%$ & 2 & $0.3 \%$ & \multirow{2}{*}{ - } & \multirow{2}{*}{1.000} \\
\hline No & 92 & $100.0 \%$ & 602 & $99.7 \%$ & & \\
\hline \multicolumn{7}{|l|}{ GI Bleeding } \\
\hline Yes & 0 & $0.0 \%$ & 1 & $0.2 \%$ & \multirow{2}{*}{ - } & \multirow{2}{*}{1.000} \\
\hline No & 92 & $100.0 \%$ & 603 & $99.8 \%$ & & \\
\hline \multicolumn{7}{|c|}{ Groin Hematoma } \\
\hline Yes & 0 & $0.0 \%$ & 1 & $0.2 \%$ & \multirow{3}{*}{-} & \multirow{3}{*}{1.000} \\
\hline No & 92 & $100.0 \%$ & 603 & $99.8 \%$ & & \\
\hline Total & 92 & $100.0 \%$ & 604 & $100.0 \%$ & & \\
\hline
\end{tabular}




\section{Discussion}

The choice for finest treatment for coronary artery disease in the elderly have always been a difficult task given that the elderly patients had more risk factors and also faced more side effects of the drugs due to differences in its absorption, metabolism, distribution and excretion.

The outcomes of PTCA in the elderly group had a high success rate (96\%). But there were some cases of in-hospital death caused by the complications after the procedure. The causes of death in the elderly were not directly related to PTCA/Stenting but rather due to the complications of the risk factors and other co-morbidities.

Studies from other centres have also reported a similar trend. For example, a Polish study published in 2007 reported a high rate of success in elderly who had undergone PTCA but there were still unfavourable procedural outcomes and in-hospital deaths.

Earlier on, in the early 1980's PTCA had been hailed as a very good alternate to CABG in the elderly patients and had similar outcomes when compared to the younger patients ${ }^{2,3}$. However, later on, there were reports of problems associated with revascularization in the elderly. For example, Salley and colleagues mentioned in their 1993 article that 'the management of ischemic heart disease in the elderly is complex' and that 'invasive therapies such as percutaneous transluminal coronary angioplasty (PTCA) and coronary artery bypass grafting (CABG) are associated with significant morbidity and mortality' ${ }^{1}$. That more cautious approached was required in the elderly and that not all lesions would be suitable for stenting was remarked by Kowalchuk and colleagues in 1990 when they reported that only $31 \%$ of the lesions were amenable to stentin ${ }^{4}$. But at the turn of the millennium, reports of a positive short term and long term results, comparable to those of the younger patients, started pouring in-credited mostly to the advent of drug-eluting stents and increasing use of IIb/IIla antagonists ${ }^{5}$.

\section{Conclusion}

Though the outcome in the elderly is poorer in comparison to the younger patients, it is an expected result when compared to even the biggest centres worldwide. However, the study does point out the need to be extra vigilant when procedures such as angioplasty are performed in the elderly patients.

\section{References}

1. Salley RK, Robinson MC. Ischemic heart disease in the elderly: the role of coronary angioplasty and coronary artery bypass grafting. South Med J. 1993 Oct;86(10):2S15-22.

2. Mock MB, Holmes DR Jr, Vlietstra RE, Gersh BJ, Detre KM, Kelsey SF, Orszulak TA, Schaff HV, Piehler JM, Van Raden MJ, et al. Percutaneous transluminal coronary angioplasty (PTCA) in the elderly patient: experience in the National Heart, Lung, and Blood Institute PTCA Registry. Am J Cardiol. 1984 Jun 15;53(12):89C-91C.

3. Mills TJ, Smith HC, Vlietstra RE. PTCA in the elderly: results and expectations. Geriatrics. 1989 Jul;44(7):71-2, 77-9.

4. Kowalchuk GJ, Siu SC, Lewis SM. Coronary artery disease in the octogenarian: angiographic spectrum and suitability for revascularization. Am J Cardiol. 1990 Dec 1;66(19):1319-23.

5. Liistro F, Colombo A. Coronary angioplasty in elderly patients. Ital Heart J Suppl. 2002 Jan; 3(1):1-8. 